hand, if it fits all the observed values without omitting any, would be much more convincing than a linear law which ignores one third of the data. The remarkably close agreement of Edmondson's sine law of variation ${ }^{2}$ with the observations cannot be fully appreciated without a graphical representation such as that reproduced as Fig. 1; it is significant, particularly because of its simplicity and because the period is the longest possible : a sinusoid which would 'pick up' Perrotin's value artificially by a multiplicity of undulations due to a short period would carry no conviction whatever to my mind, but the manner in which the graph 'picks up' (in passing, so to speak) this isolated value of 1902 is most remarkable and, in my opinion, convincing. Such a nine-fold coincidence cannot be fortuitous.

M. E. J. Gheury de Bray.

40, Westmount Road,

Eltham, S.E.9.

May 24.

1 Astr. Nachr., No. 5520: 1927. L'Astronomie, November 1927. ${ }^{2}$ NATURE, 183, 759, May 19, 1934

\section{Abnormal Permeability Produced in a Steel Wire by Loading}

USING the ballistic method previously described ${ }^{1}$, recent investigations have shown that an abnormally high value for the permeability of a steel wire can be obtained by loading.

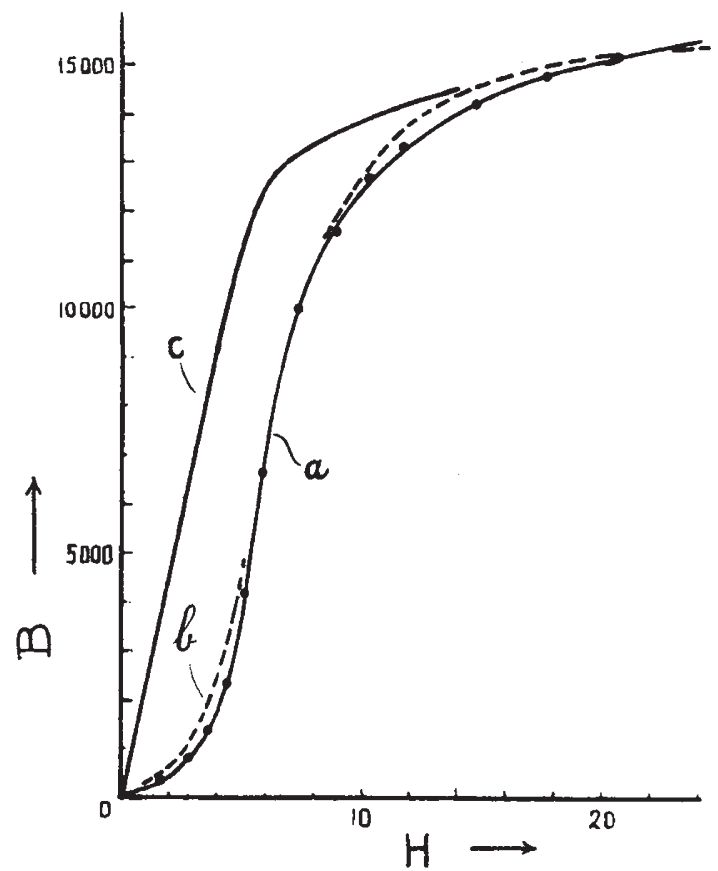

FIG. 1 .

In Fig. 1, the curve $a$ shows the relationship of $B$ and $H$ obtained by the ordinary method of reversals for a mild steel wire of $0.092 \mathrm{in}$. diameter, the wire being unloaded. Curve $b$ shows the values of $B$ and $H$, also obtained by the method of reversals, when the wire was supporting a steady load of $202 \mathrm{lb}$. (that is, a stress of $13 \cdot 7$ tons per sq. inch).

By means of the ballistic test described ${ }^{1}$, the increase of induction density $\triangle B$ was obtained as a function of $H$ when a load of $202 \mathrm{lb}$. was gently applied. Before each application of the load, the magnetic intensity was raised to a value of about 200 gauss and the desired value of $H$ was then reached by reversing the exciting current of the solenoid many times. The curve $c$ in Fig. 1 has been obtained by adding the value $\Delta B$ to the corresponding value of $B$ given by the curve $a$. It is seen that, for low values of $H$, the permeability given by curve $c$ is more than ten times the normal value of the permeability as given by the curve $a$.

Loading the wire when it is placed in a steady magnetic field of suitable intensity gives rise to a very marked increase of permeability.

By means of a somewhat different procedure, Ewing ${ }^{2}$ obtained very large increases of induction when an iron wire, which had previously been stretched beyond its elastic limit, was loaded. For annealed iron wire, however, the effect was very much less. So far as I am aware, the results now given are the first yet recorded showing the immense increase of induction produced by loading an unfatigued steel wire.

$$
\text { T. F, WALL. }
$$

Department of Electrical Engineering, University, Sheffield, 1. May 10.

1 NATURE, 132, 513, Sept. 30, 1933.

Phil. Trans., 1885.

\section{A Haploid Plant of Nicotiana sylvestris}

Aтtempts to produce a merogonic fully developed animal organism have been unsuccessful; plants appear to be more convenient subjects for this purpose. We know two androgenic haploids at the present time and both belong to the genus Nicotiana. One was produced by pollinating a triploid Nicotiana Tabacum plant $(2 n=72)$ with $N$. Langsdorffi $(2 n=18)$. From such a cross a Nicotiana Langsdorffii androgenic haploid with 9 somatic chromosomes was produced $^{1}$. The other androgenic haploid was produced by pollinating the amphidiploid $N$. glutinos $a \times$ $N$. Tabacum $=N$. digluta with $N$. Tabacum $(2 n=48)$. From such a cross an androgenic N. Tabacum with 24 somatic chromosomes has been produced ${ }^{2}$.

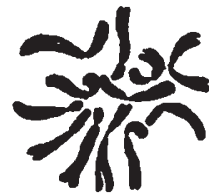

Fic. 1. Somatic metaphase from a root tip of the haploid Nicotiana sylvestris.

Recently we produced another Nicotiana haploid by pollinating the $F_{1}$ hybrid $N$. Tabacum $\times N$. sylvestris with pollen from $N$. sylvestris $(2 n=24)$. Considering the former two cases, it seems very probable that the haploid thus produced has developed from a sperm nucleus. The haploid is a dwarf Nicotiana sylvestris plant with smaller cells than the normal (diploid) N. sylvestris. The haploid has two chromosomes with small heads, two with large heads (subterminal constriction), four with medial constrictions and four with submedial constrictions (Fig. 1). In the root tips of the haploid plant, single cells or even.whole sectors were found with diploid chromosomal constitution - a condition which often occurs in haploids.

It is most probable that this haploid has developed 